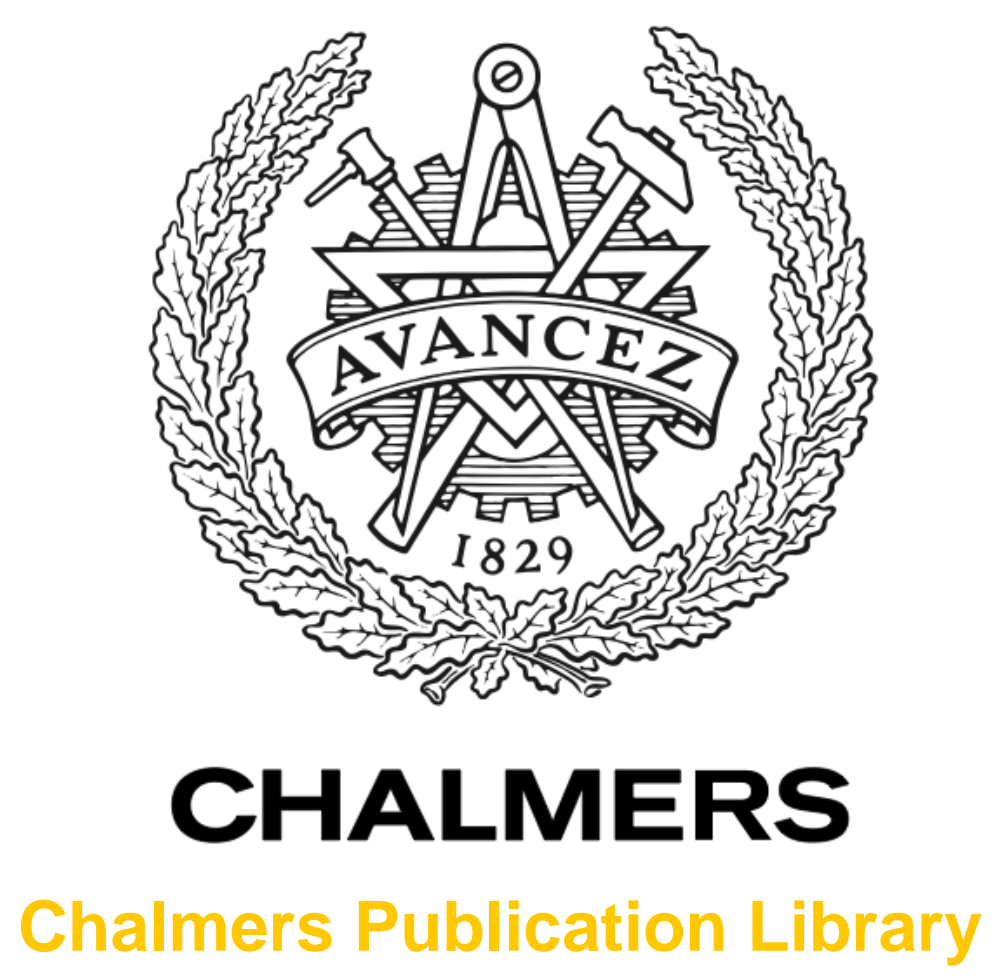

\title{
Framework methodology for increased energy efficiency and renewable feedstock integration in industrial clusters
}

This document has been downloaded from Chalmers Publication Library (CPL). It is the author's version of a work that was accepted for publication in:

Applied Energy (ISSN: 0306-2619)

Citation for the published paper:

Hackl, R. ; Harvey, S. (2013) "Framework methodology for increased energy efficiency and renewable feedstock integration in industrial clusters". Applied Energy

http://dx.doi.org/10.1016/j.apenergy.2013.03.083

Downloaded from: http://publications.lib.chalmers.se/publication/179401

Notice: Changes introduced as a result of publishing processes such as copy-editing and formatting may not be reflected in this document. For a definitive version of this work, please refer to the published source. Please note that access to the published version might require a subscription. 


\title{
FRAMEWORK METHODOLOGY FOR INCREASED ENERGY EFFICIENCY AND RENEWABLE FEEDSTOCK INTEGRATION IN INDUSTRIAL CLUSTERS
}

\author{
Roman Hackl ${ }^{1, *}$, Simon Harvey ${ }^{1}$ \\ ${ }^{1}$ Department of Energy and Environment, Division of Heat and Power Technology \\ Chalmers University of Technology, Kemivägen 4, 41296 Gothenburg, Sweden \\ e-mail: roman.hackl@chalmers.se, simon.harvey@chalmers.se
}

*Corresponding author Tel: +46 31772 3861, Fax: +46 31 821928, E-mail: roman.hackl@chalmers.se

\begin{abstract}
Energy intensive industries, such as the bulk chemical industry, are facing major challenges and adopting strategies to face these challenges. This paper investigates options for clusters of chemical process plants to decrease their energy and emission footprints. There is a wide range of technologies and process integration opportunities available for achieving these objectives, including (i) decreasing fossil fuel and electricity demand by increasing heat integration within individual processes and across the total cluster site; (ii) replacing fossil feedstocks with renewables and biorefinery integration with the existing cluster; (iii) increasing external utilization of excess process heat wherever possible. This paper presents an overview of the use of process integration methods for development of chemical clusters. Process simulation, pinch analysis, Total Site Analysis (TSA) and exergy concepts are combined in a holistic approach to identify opportunities to improve energy efficiency and integrate renewable feedstocks within such clusters. The methodology is illustrated by application to a chemical cluster in Stenungsund on the West Coast of Sweden consisting of 5 different companies operating 6 process plants. The paper emphasizes and quantifies the gains that can be made by adopting a total-site approach for targeting energy efficiency measures within the cluster and when investigating integration opportunities for advanced biorefinery concepts compared to restricting the analysis to the individual constituent plants. The holistic approach applied highlights the significant potential improvement to energy and emissions footprints that can be achieved when applying a total site approach.
\end{abstract}

Keywords: total site analysis (TSA), biorefinery, process integration, energy efficiency, renewable feedstock materials

\section{NONMENCLATURE}

$\begin{array}{ll}\text { Abbreviation } & \\ \text { CC } & \text { Composite Curves } \\ \text { CW } & \text { Cooling Water } \\ \text { ECC } & \text { Exergy Composite Curves } \\ \text { EDC } & \text { Dichloroethane } \\ \text { GCC } & \text { Grand Composite Curve } \\ \text { IEA } & \text { International Energy Agency } \\ \text { LP } & \text { Low Pressure (steam) } \\ \text { PVC } & \text { Polyvinyl Chloride } \\ \text { TSA } & \text { Total Site Analysis } \\ \text { TSC } & \text { Total Site Composites } \\ \text { TSP } & \text { Total Site Profiles } \\ \text { VCM } & \text { Vinyl Chloride }\end{array}$




$\begin{array}{ll}\text { Symbols } & \\ \Delta E x_{\mathrm{p}} & \text { Exergy flow rate difference in the process [W] } \\ \Delta E x_{\mathrm{u}} & \text { Exergy flow rate difference in the utility system [W] } \\ T & \left.\text { Temperature [ }{ }^{\circ} \mathrm{C}\right] \\ \Delta T_{\min } & \text { Minimum Temperature difference [K] } \\ Q_{\text {consumed }} & \text { Utility used for process heating/cooling [W] } \\ Q_{\text {cooling,min }} & \text { Minimum cooling demand [W] } \\ Q_{\text {gen }} & \text { Utility generated in the process [W] } \\ Q_{\text {heating,min }} & \text { Minimum heating demand [W] } \\ P & \text { Actual shaft power [W] }\end{array}$

\section{INTRODUCTION}

\subsection{Background}

According to the International Energy Agency's latest Energy Technology Perspectives 2012 report [1] energy related global $\mathrm{CO}_{2}$ emissions must be cut to half of current levels by 2050 and continue to decrease afterwards in order to curb the global temperature increase to $2{ }^{\circ} \mathrm{C}$. Increased end-use fuel and electricity efficiency is seen as one of the most important technologies to reach the $2{ }^{\circ} \mathrm{C}$ goal. High efficiency in industrial production processes is of utter importance to stay competitive and achieve sustainability. Energy-intensive chemical plants consume large amounts of utilities (e.g. steam, Cooling Water (CW) and electricity) in order to operate their processes. Furthermore, many such plants are based on fossil oil feedstocks and energy carriers.

This paper discusses a framework methodology for investigating options to increase energy efficiency and renewable feedstock usage in industrial clusters. The work is based on a number of studies related to a chemical cluster located in Stenungsund, Sweden, that have been conducted by the authors' research group at Chalmers University of Technology. The potential for site-wide heat integration throughout the cluster was investigated in reference [2]. A more practical investigation of the identified measures was performed by Andersson et al. [3]. Potential biorefinery processes for integration with the chemical cluster were identified by Hackl et al. [4], and a biorefinery integration study for a process producing ethylene from lignocellulosic biomass was performed [5]. The cluster consists of six chemical process sites operated by five companies. These companies recently adopted a common goal to increase the share of renewable feedstock and products in the cluster and at the same time increase the overall energy efficiency of the cluster site. The scientific literature includes a number of studies investigating improved energy efficiency of industrial clusters. Matsuda et al. used R-curve analysis and Site Source Sink Profiles to investigate heat integration opportunities within Japan's largest chemical complex [6]. Stijepovic and Linke propose a methodology to target for waste heat recovery and use in industrial zones [7]. The sitewide heat integration potential of the cluster used as a case study in this paper was investigated by Hackl et al. [8]. A number of investigations of opportunities for integration of biomass based processes with existing industrial process plants have been conducted by the authors' group, including case studies in the pulp and paper [9], petrochemical [10], refinery industry [11] and the power sector [12]. An overview of systems perspectives on biorefineries is given by Sandén [13]. Duić [14] presents a summary of the 6th Dubrovnik Conference on Sustainable Development of Energy, Water and Environment Systems which to a large extent deals with energy efficiency and integration of renewable materials.

Figure 1 illustrates the energy and material flows into, within and out from a typical chemical cluster (left side of Figure 1). Large amounts of fossil feedstocks, fuels and electricity are imported 
and converted into products and large amounts of excess heat. In the cluster investigated in this work, only material flows are currently exchanged across company borders. Almost no energy collaboration occurs [8]. The aim is to identify measures to convert an existing industrial cluster to become more energy efficient and less depending on fossil resources. A possible vision of the converted cluster is illustrated to the right in Figure 1. The major changes are:

- Decreased import of fossil feedstocks, fuels and electricity

- Integration of biorefinery processes to decrease the clusters' fossil feedstock dependence

- More efficient use of excess heat

- Export of by-products.

These improvements can be accomplished by:

- Increased energy efficiency of single plants

- Increased energy efficiency by site-wide energy collaboration; whereby companies send excess heating and cooling capacity to other plants for optimal re-use

- Implementation of process integrated biorefinery units

- Increased utilization of low grade excess heat, which cannot be recovered directly in the processes, e.g. extended district heating, low temperature refrigeration/electricity generation, heat pumping and biomass drying [15]

- Increased co-generation.

This paper presents a framework for investigating opportunities for implementing such improvements in a systematic way.

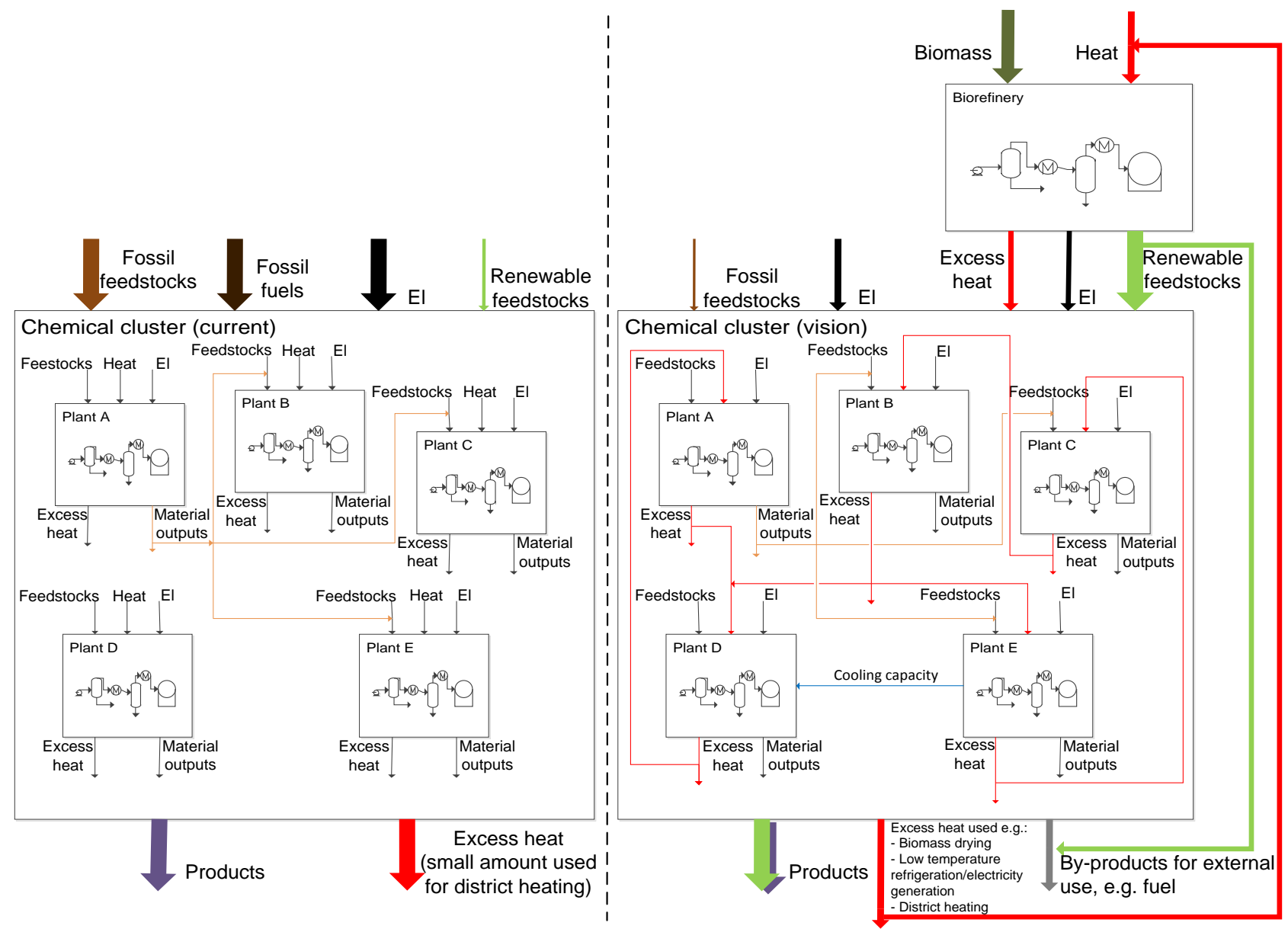

Figure 1 Left: Illustration of energy and material flows in an industrial cluster with a low degree of integration (no heat integration, only material integration); Right: Energy and material flows in an industrial cluster with high degree of integration (heat and material integration) and integrated on-site processing of renewable feedstocks (biorefinery concept). 


\subsection{Energy Efficiency in Industrial Clusters}

Industrial clusters offer major opportunities for energy conservation that can be achieved by increased site-wide energy collaboration and process integration [8].

From an energy efficiency point of view the short distances between the companies located in a cluster enable the exchange of heat and cooling between the different process plants, thereby increasing the overall energy efficiency of the cluster. A company which has an excess of heat at a temperature level which does not allow it to be utilized within its own plant can export this heat to a neighbouring plant. This reduces the need to produce the same amount of heat in a utility boiler, thus saving primary energy. Total Site Analysis (TSA) [16] methodology can be used to target for such energy collaboration opportunities. However, one of the barriers to implementation of such collaborative measures is often the ownership structure of the cluster. If the constituent plants have different owners, and operate in different markets with different business cycles, adopting common energy efficiency measures can present major challenges. Hence, it is important to also assess the potential for energy efficiency improvement if each plant adopts measures at its own site only, and use this as a benchmark for collaborative energy efficiency measures.

The Stenungsund chemical cluster: the largest plant and the heart of the cluster considered in this paper to illustrate the proposed framework methodology is a steam cracker plant operating with fossil feedstock such as naphta. It delivers both feedstock (mostly ethylene and propylene) and fuel gas to the other plants.

Each plant has its own utility system. Currently there is only minor collaboration in terms of heat exchange between the different plants, thus there is no coordination between plant sites regarding choice of utility levels. In total 13 different steam levels (ranging from gauge pressure of 85 bar to 1 bar), 3 different hot water systems, hot oil and flue gas heating together with water, air and refrigerant cooling are operated within the cluster. Table 1 shows the utilities used for heat and cooling recovery and process heating/cooling, together with the corresponding heat loads and amount of heat that has to be covered by external heat/cooling from the boilers and refrigeration systems. It can be seen that the total external heating demand of the cluster is $Q_{\mathrm{gen}}-Q_{\text {consumed }}=122.1 \mathrm{MW}$ and the external cooling demand is $632.8 \mathrm{MW}$. Approximately 10 MW of excess heat from two plant sites is currently delivered to the local district heating system. [8]

Table 1 Utilities currently used for heat/cooling recovery and process heating/cooling [8,17]

\begin{tabular}{lcccc}
\hline \multicolumn{1}{c}{ Utility } & $T\left[{ }^{\circ} \mathrm{C}\right]$ & $Q_{\text {gen }}[\mathrm{MW}]^{1}$ & $Q_{\text {consumed }}[\mathrm{MW}]^{2}$ & $\begin{array}{c}Q_{\text {,gen }}{ }^{-} \\
Q_{\text {consumed }} \\
{[\mathrm{MW}]}\end{array}$ \\
\hline Steam 85 bar & 300 & 50.8 & 1 & 49.8 \\
Steam 40 bar & 250 & 42 & 43.2 & -1.2 \\
Steam 28 bar & 230 & & 6.3 & -6.3 \\
Steam 20 bar & 215 & 29 & 38.5 & -9.5 \\
Steam 14 bar & 200 & 15.2 & 12.7 & 2.5 \\
Steam 10 bar & 184 & 22.1 & 21 & 1.1 \\
Steam 8.8 bar & 178 & 27.3 & 91 & -63.7 \\
Steam 7 bar & 168 & & 15.3 & -15.3 \\
Steam 6 bar & 163 & & 14.2 & -14.2 \\
Steam 4 bar & 150 & 26.1 & 2.2 & 23.9 \\
Steam 2.7 bar & 140 & 13 & 4.7 & -73.1 \\
Steam 2 bar & 131 & 55.3 & 128.4 & -7.8 \\
Steam 1 bar & 119 & 0.6 & 8.4 & -1.9 \\
Hot oil & 277 & & 1.9 & -4.3 \\
Hot water & $160-50$ & 9 & 13.3 &
\end{tabular}




\begin{tabular}{|c|c|c|c|c|}
\hline Flue gas & 1400 & & 10.4 & -10.4 \\
\hline Sum hot utility & & 290.4 & 412.5 & -122.1 \\
\hline Refrigerant $\mathrm{C} 3 / 9^{\circ} \mathrm{C}$ & 9 & 27.7 & 32.5 & -4.8 \\
\hline Refrigerant $\mathrm{C} 3 /-21^{\circ} \mathrm{C}$ & -21 & 1.2 & 20.5 & -19.3 \\
\hline Refrigerant $\mathrm{C} 3 /-40^{\circ} \mathrm{C}$ & -40 & & 38.3 & -38.3 \\
\hline Refrigerant $\mathrm{C} 2 /-62^{\circ} \mathrm{C}$ & -62 & & 0.9 & -0.9 \\
\hline Refrigerant $\mathrm{C} 2 /-84{ }^{\circ} \mathrm{C}$ & -84 & & 7.3 & -7.3 \\
\hline Refrigerant $\mathrm{C} 2 /-100^{\circ} \mathrm{C}$ & -100 & & 1 & -1.1 \\
\hline Sum refrigerant & & 29 & 100.6 & -71.7 \\
\hline $\mathrm{CW}$ & & & 472.8 & -472.8 \\
\hline Air & & & 88.2 & -88.2 \\
\hline Sum cold utility & & 29 & 662 & -632.7 \\
\hline
\end{tabular}

\subsection{Integration of Biorefineries in Industrial Clusters}

The biorefinery concept is a way to substitute fossil hydrocarbon feedstock in processes for production of synthetic products and liquid fuels by renewable raw materials. A wide range of renewable feedstock materials can be converted into value added products and therefore substitute fossil feedstocks. The role of biorefineries is according to the definition of the IEA "the sustainable processing of biomass into a spectrum of marketable products and energy" [18].

The raw materials that can be used as feedstock for a biorefinery are, for example, crops and residues, lignocellulosic material, municipal solid waste and algae. They can be provided by four different sectors: agriculture, forestry, industries and aquaculture. Biorefineries apply a wide range of technologies to separate the biomass inputs into their building blocks, such as hydrogen, carbohydrates and proteins, which then are converted into value added products [19].

Integration of a biorefinery process within an industrial cluster can often be advantageous compared to stand-alone operation for the following reasons [20]:

- Existing infrastructure e.g. boilers, piping, storage

- Low grade excess heat from the cluster can be used for biomass drying

- Excess heat from certain types of biorefinery (e.g. excess steam from a gasification unit) can partly cover the heat demand in other parts of the cluster

- Certain types of biorefinery products can be used directly as feedstock elsewhere in the cluster (syngas, ethanol etc.)

- Biorefinery operations can capitalize on existing knowhow on operation of chemical process.

\subsection{Aim}

In this paper a holistic approach is suggested to identify opportunities for increased energy efficiency and integration of biogenic feedstock with existing industrial process clusters. The proposed framework methodology involves systematic application of a basket of established process integration tools which if combined in the suggested way can be used to identify:

- cost-effective measures to decrease the energy footprint of industrial clusters

- energy-efficient ways to integrate biorefinery operations and/or switch to renewable feedstocks

- biorefinery topologies most suitable for integration with the given cluster 


\section{METHODOLOGY}

\subsection{Overview}

High energy efficiency is a key parameter for achieving a higher degree of sustainability within industrial clusters. The proposed framework methodology is based upon experience gained from case studies conducted by the authors' group in connection with the chemical cluster in Stenungsund [2-5]. The methodology is based on a holistic representation of the energy system of the overall cluster. Figure 2 shows an overview of how a number of process integration tools are combined in the framework methodology.

In the first step, data for individual process heating and cooling demands are collected. The level of detail at which a single plant is investigated must be decided on at this point. Three different approaches are available. In the black-box approach, only data on heat flows to and from a single plant via the utility system is collected. In the grey-box approach, data on heat flows to and from single process streams within a plant via the utility system is collected. Only process streams which are heated or cooled by utility are included. Process streams which exchange heat with another process stream are not included, which implies that the plant's current level of heat integration is accepted. The most detailed analysis is performed using the white-box approach, in which data for TSA is taken from a thorough pinch analysis study, accounting for all process stream heating and cooling requirements within the single plant [21].

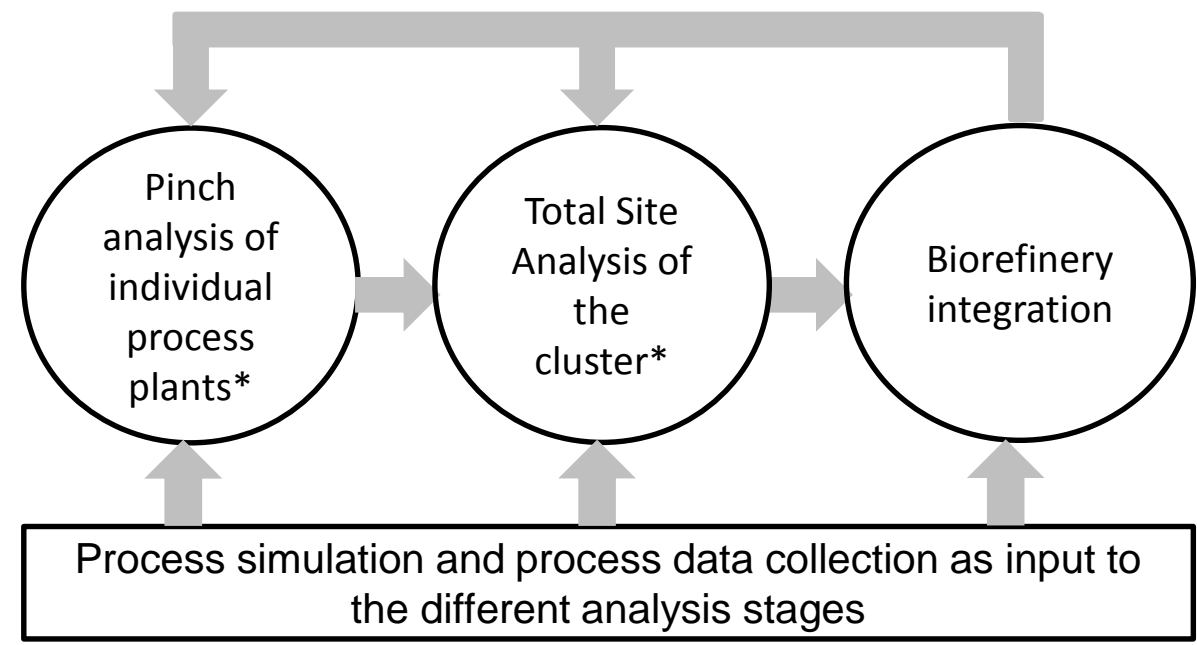

*Processes where heating and cooling demand are coupled to mechanical and electrical energy use (e.g. refrigeration systems) a combination of PA and exergy analysis is used

Figure 2 Illustration of the framework methodology.

In the second step the data collected is analysed using TSA tools. Total site heating and cooling profile curves are produced that provide an overview of heat flows within the total site's energy system, and opportunities for exchange of utility flows between plants can be identified. A detailed analysis of the TSA curves allows the user to identify potential heat integration improvements that require a common site-wide utility system. Thereby the theoretical minimum overall hot and cold utility demand is determined. Practical measures to approach this minimum heating and cooling demand can thereafter be identified. If reduced heating and cooling demands are coupled to reduced shaft power demand (e.g. reduced refrigeration requirements decrease the shaft power required to drive the refrigeration system compressors), a combination of pinch analysis and exergy analysis can be used to assess the total savings of hot and cold utility. 
In the third step opportunities for integration of biorefinery processes are investigated. The knowledge of the current energy system of the cluster and the potential for further site-wide integration (determined in steps one and two) is the basis for identifying opportunities for energy efficient biorefinery integration. Process simulation is used to obtain mass and energy balances of the biorefinery process. The efficiency gain that could be achieved by integrating the biorefinery with the existing cluster is quantified by first conducting pinch analysis of the single biorefinery process followed by total site analysis for integration with the cluster. This procedure is performed for several promising biorefinery concepts in order to identify the most suitable for integration with the existing cluster.

Regardless of the level of heat integration, there is always some excess heat rejected from the processes. There are several technologies available for utilisation of excess heat. A complete inventory of the amount and temperature levels of excess heat available from the processes should be conducted and options for using this residual heat should be explored.

\subsection{Process simulation}

A very suitable definition of process simulation is given by Thomé (1993) [22]:

"Simulation is a process of designing an operational model of a system and conducting experiments with this model for the purpose either of understanding the behavior of the system or of evaluating alternative strategies for the development or operation of the system. It has to be able to reproduce selected aspects of the behavior of the system modeled to an accepted degree of accuracy."

When necessary data was not available in the form of plant measurements, design data and other literature, the process simulation software Aspen Plus (v. 7.2) [23] was used in this work to establish mass and energy balances of:

- Unit operations in several processes for which measured data was not available.

- Biorefinery processes in the development stage.

\subsection{Pinch Analysis}

Pinch analysis is a commonly used targeting method for heat integration of chemical processes. The method was developed by Bodo Linnhoff [24] and is thoroughly described by e.g. Kemp [25], Smith [26] and Klemes et al. [27]. Pinch analysis is applied to single plants and thereby serves several purposes, including:

- Targeting for minimum heating and cooling demands

- Targeting for optimal loads and temperature levels for process utilities

- Identifying energy efficiency measures in individual process plants

- Providing necessary stream data input to the TSA

Total Site Analysis

Total Site Analysis (TSA) represents an extension of the pinch analysis method and is widely applied to industrial sites to target for increased energy efficiency via a common utility system. The TSA concept was introduced by Dhole and Linnhoff [28] and further developed by Raissi [16].

TSA is used to integrate the individual heating and cooling demands of different processes within a total site. Excess heat from one process plant is transferred to a common utility system (e.g. steam, hot water, hot oil) and then delivered to processes with a heat deficit. The TSA method enables the amounts of hot utility generated and used by the combined individual processes, the amount of heat recovery in a common hot utility system, the steam demand from the boilers and the cogeneration potential to be determined [29]. 
Guidelines for heat integration strategies for petrochemical complexes have been proposed by Feng et al. [30]. The use of individual process Grand Composite Curves (GCC) for integration of different processes in a TSA study is further discussed by Bandyopadhyay et al. [31]. The importance of including sensible heat when matching process and steam systems in TSA was demonstrated by Botros and Brisson [32].

TSA is used to establish targets for the minimum heating and cooling demand of the overall cluster if it is assumed that excess heating and cooling capacity can be transferred from one plant to another via a common utility system. TSA also provides insights necessary to make specific changes to the site's utility systems in order to reach the targets identified for the minimum heating and cooling demands.

\section{Combined Pinch Analysis and Exergy Analysis}

Primary energy savings achieved by heat integration measures that reduce cooling capacity delivered by refrigeration systems cannot be directly evaluated using regular pinch analysis. Linnhoff and Dhole [33] developed a methodology which enables targeting for shaft power savings in low temperature processes by combining exergy and pinch analysis concepts. The main difference compared to conventional pinch analysis is that the Composite Curves (CC) and GCC plot the Carnot efficiency corrected temperature instead of temperature. The Carnot efficiency is defined by $\eta_{\mathrm{c}}=1-T_{\text {ref }} / T\left(T_{\text {ref }}=\right.$ reference temperature). An example of such a curve is shown in Figure 3.

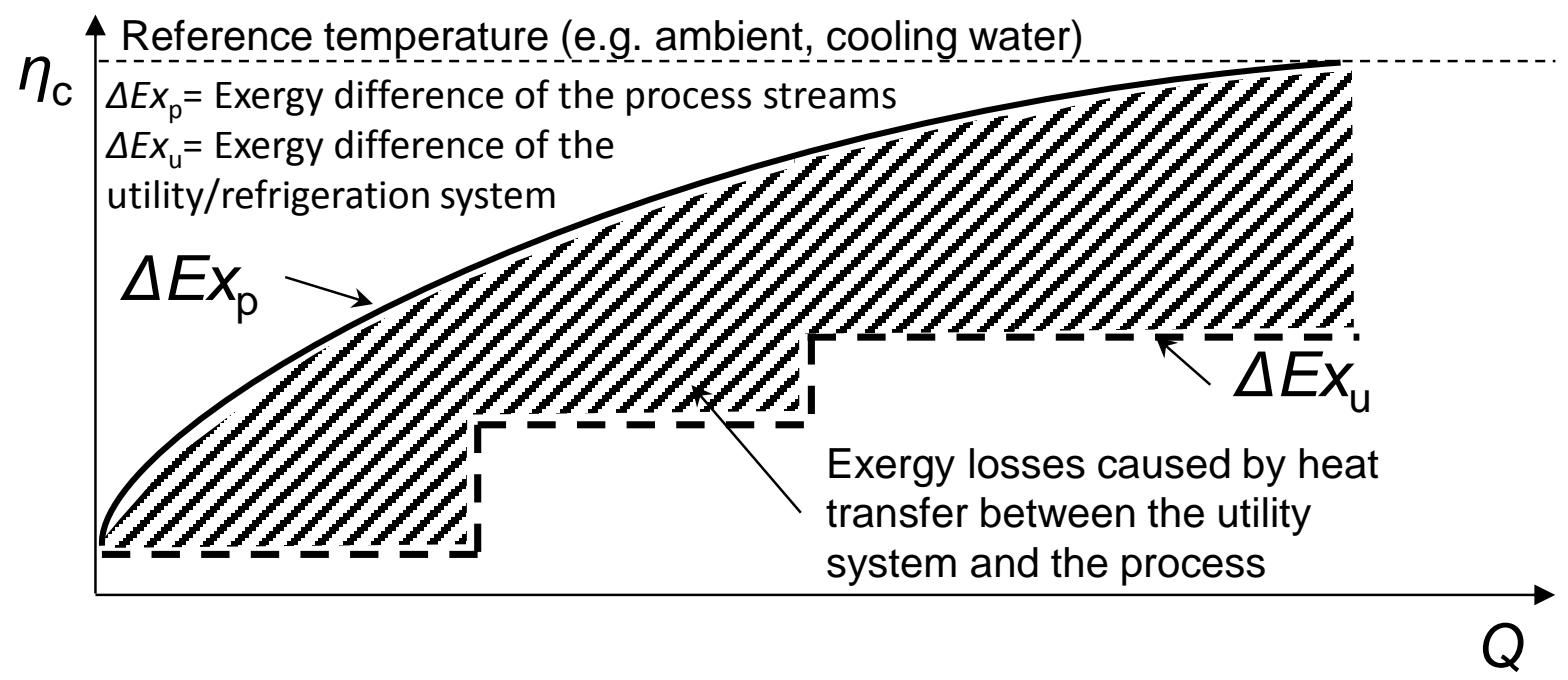

Figure 3: A schematic example of a exergy CC showing the composite curve of the process, composite curve of the utility system, the resulting exergy flow rate difference of the process streams and the utility system and the exergy flow rate losses caused by heat transfer between the utility system and the process [33].

The area between the respective curve and the reference temperature line in the exergy CC represents the theoretical amount of exergy flow rate that must be supplied in order to achieve the desired target temperature. The area between the process (full) line and the utility system (dashed) line represents the exergy flow rate losses caused by the utility system design (cooling temperature levels, $\Delta T$, etc.). The presented curves are used to target for reduction of the exergy flow rate losses by identifying changes to the utility system

The areas shown in the Carnot efficiency based curves represent exergy flow rate differences. In order to estimate the real shaft power requirement, the exergetic efficiency of the system investigated must be taken into account. This can be expressed by $\eta_{e x}=\Delta E x_{\mathrm{u}} / P$. The theoretical exergy flow rate difference $\left(\Delta E x_{\mathrm{u}}\right)$ is obtained from the exergy $\mathrm{CC}$ of the real refrigeration system 
and the actual shaft-power $(P)$ for the investigated process is obtained from measurements or process simulation of the refrigeration system. For the refrigeration system investigated in this study an exergetic efficiency of 0.66 was determined, by using measured shaft power data obtained for the targeted refrigeration systems.

\section{RESULTS}

\subsection{Pinch analysis of individual plants within the cluster}

Step one in the suggested framework methodology is pinch analysis of the individual process plants. Hereafter, the results of pinch analysis of the Vinyl chloride (VCM) production section of the PVC plant are presented. The results presented are based on an MSc thesis project performed at the Division of Heat and Power Technology at Chalmers University of Technology [34].

The PVC production plant is located within the chemical cluster in Stenungsund. The plant is expected to expand in the near future. This provides the opportunity to implement major process changes, including investments in energy efficiency measures. Furthermore, the expanded plant will have a higher energy usage, which makes investments in energy efficiency even more attractive to avoid investments in increased boiler capacity.

The PVC production process can be divided into three steps, as shown in Figure 4. In the first step (chlorine production) an $\mathrm{NaCl}$ (sodium chlorine) solution is converted into $\mathrm{NaOH}$ (sodium hydroxide), hydrogen and chlorine by electrolysis. In the future the electrolysis unit will be replaced by a more energy-efficient membrane unit. The main energy carrier is electricity and therefore the potential for heat integration is low. The next step in the PVC production process is the VCM production plant. Chlorine and ethylene are converted into EDC (dichloroethane), which is then further converted into VCM in a cracking furnace. In the final step the VCM is polymerized in batch reactors and thereafter dried in steam/flue gas dryers.

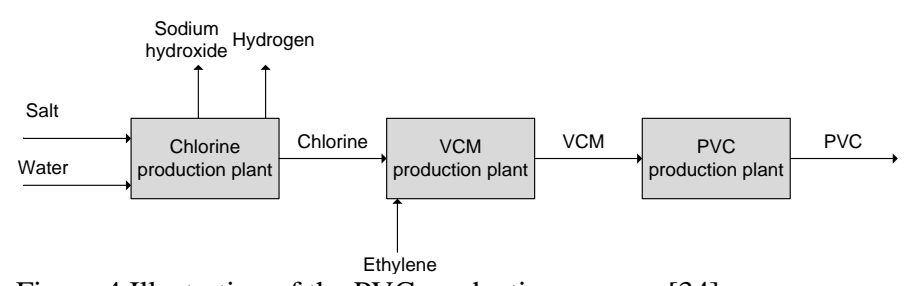

Figure 4 Illustration of the PVC production process [34].

In current process operations, no heat is transferred between the three different sub-processes. The steam demand of the plant is covered by a steam boiler.

In this pinch analysis study only the VCM production plant is investigated, since it is here that the highest heat energy savings potential is expected. The PVC production process contains mostly batch processes which are difficult to integrate with other, continuous processes.

In the pinch analysis study the potential for increased heat recovery within the PVC plant was investigated. Three different options for increasing energy efficiency were identified:

- Increased internal heat exchange within the VCM plant

- Export of excess heat to other parts of the PVC production process

- Heat pumping

The projected heating and cooling demands of the VCM plant after site expansion are $20.8 \mathrm{MW}$ and 48.9 MW. The Grand Composite Curve (GCC) in Figure 5 shows the corresponding minimum heating (13.0 MW) and cooling (41.1 MW) demands of the expanded plant. The potentials for hot and cold utility savings for the expanded process are thus $7.8 \mathrm{MW}$. 


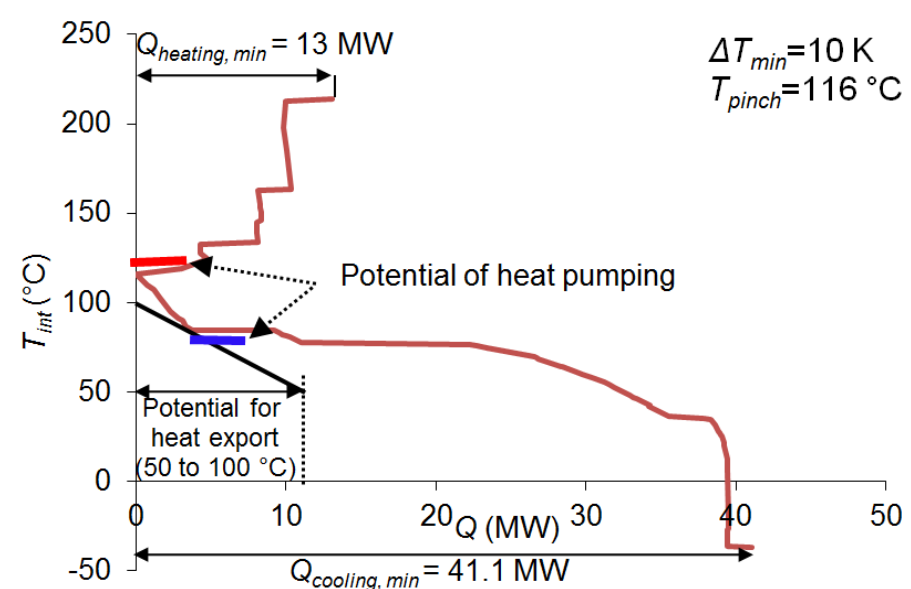

Figure 5 GCC of the VCM production plant indicating the minimum heating and cooling demand, the potential for heat export to other parts of the PVC plant and the potential for heat pumping.

Pinch analysis theory states that failure to meet energy targets is due to violation of one or several of three "Golden rules" for energy-efficient process heat recovery systems: (i) supply of hot utility below the process pinch temperature; (ii) utility cooling above the process pinch temperature; (iii) internal heat transfer within the process from above the process pinch to below the process pinch. Detailed analysis of the VCM indicated the presence of 15 pinch rule violations. 10 of these violations are heating below the pinch temperature, 4 cooling above the pinch temperature and one heat transfer through the pinch. Of these, the 5 largest violations lead to utility requirements that exceed the energy target by $6.5 \mathrm{MW}$, or $83 \%$ of the total savings potential. The remaining 10 violations result in utility savings of $1.3 \mathrm{MW}$ and each of them demanded further investments. This was deemed not economically feasible and therefore these measures were not considered for further investigation.

The largest pinch violations consist mainly of heating below the pinch (3.8 MW) and cooling above the pinch (3.7 MW). Further detail is provided in reference [34], which also provides a number of suggestions for eliminating these five violations, as well as an economic evaluation of the proposed measures showing pay-back periods between 0.43 and 1.2 years ${ }^{1}$ for the different measures. The remaining 10 pinch violations were not investigated further given their small magnitude. Costs other than heat exchanger area costs tend to dominate economics of process modifications to avoid small pinch violations, resulting in very poor economic performance. The proposed measures include heat recovery from two process hot streams (outlet stream from a reactor and from a column cooler) that are currently cooled with cold utility above the pinch. These streams can instead be used to heat 5 process streams.

Figure 5 also shows that that there are approximately $10 \mathrm{MW}$ of heat available at temperatures between 100 and $50{ }^{\circ} \mathrm{C}$, which can be used outside the VCM plant, for e.g. district heating, low temperature electricity production or for process heating at another site.

Pinch analysis was conducted for each of the six individual constituent plants within the chemical cluster. The results obtained for minimum heating and cooling demand are shown in Table 2. Note that the basis for the results shown in this table was the heating and cooling requirements of the constituent processes as operated currently, i.e. possible future operating conditions are not considered. Thus there is no line in the table corresponding to the results presented in Figure 5 (note also that Figure 5 corresponds to a sub-process of the PVC plant, not the whole plant).

Table 2 Minimum heating and cooling demand of the constituent plants within the chemical cluster.

${ }^{1}$ Pay-back period calculations do not account for costs associated with production losses during plant downtime. 


\begin{tabular}{lcc}
\hline Plant/Site & $\begin{array}{c}\text { Minimum heating demand } \\
{[\mathrm{MW}]}\end{array}$ & $\begin{array}{c}\text { Minimum cooling demand } \\
{[\mathrm{MW}]}\end{array}$ \\
\hline Plant A & 1 & 14.0 \\
Plant B & 17.3 & 60.3 \\
Plant C & 5.5 & 156 \\
Plant D & 0 & 244 \\
Plant E & 20.6 & 31.9 \\
Plant F & 27.6 & 92.1 \\
\hline Sum & 72 & 598 \\
\hline
\end{tabular}

\subsection{Site wide heat integration of the cluster}

Heat integration

The results presented in this section are obtained from previous studies conducted on the chemical cluster in Stenungsund $[2,4]$.

The first step in the analysis was the data collection for all constituent plants in the cluster. Here data from previous pinch analysis studies, process measurements and process simulation was used.

After data collection the Total Site Profiles (TSP) and the Total Site Composites (TSC) of the current cluster were constructed. The curves show that with the current utility system the cluster has a demand of external hot utility of $122 \mathrm{MW}$ and an external cold utility demand of $633 \mathrm{MW}$ (see Table 1). With help of the TSP and TSC changes to the utility system were suggested in order to create a more integrated utility system which enables for increased energy efficiency. Figure 6 shows the suggested changes to the utility system in order to make site wide process integration possible.

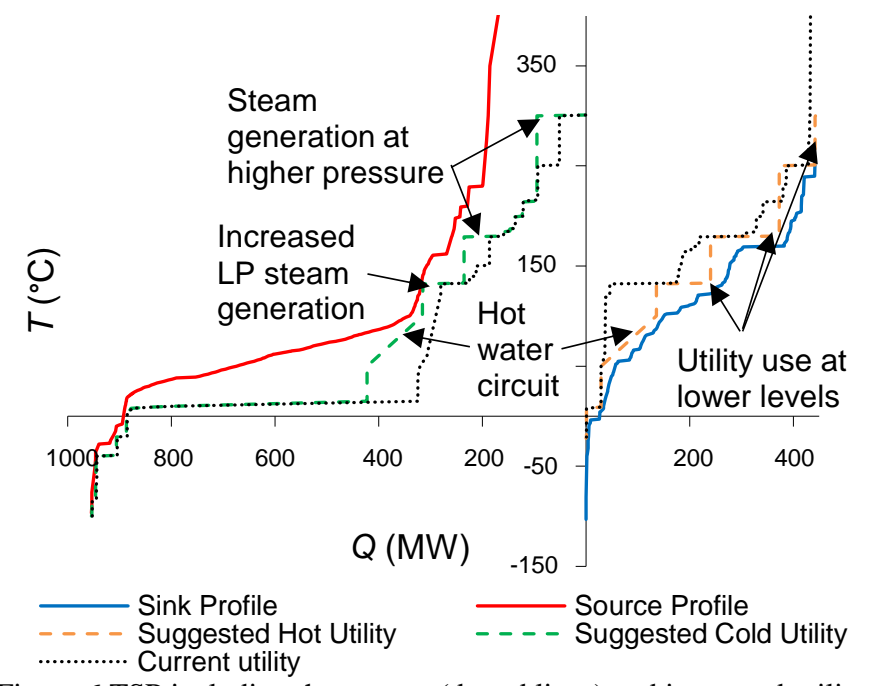

Figure 6 TSP including the current (dotted lines) and improved utility system (dashed lines). Necessary changes to the utility system are indicated [8]. 


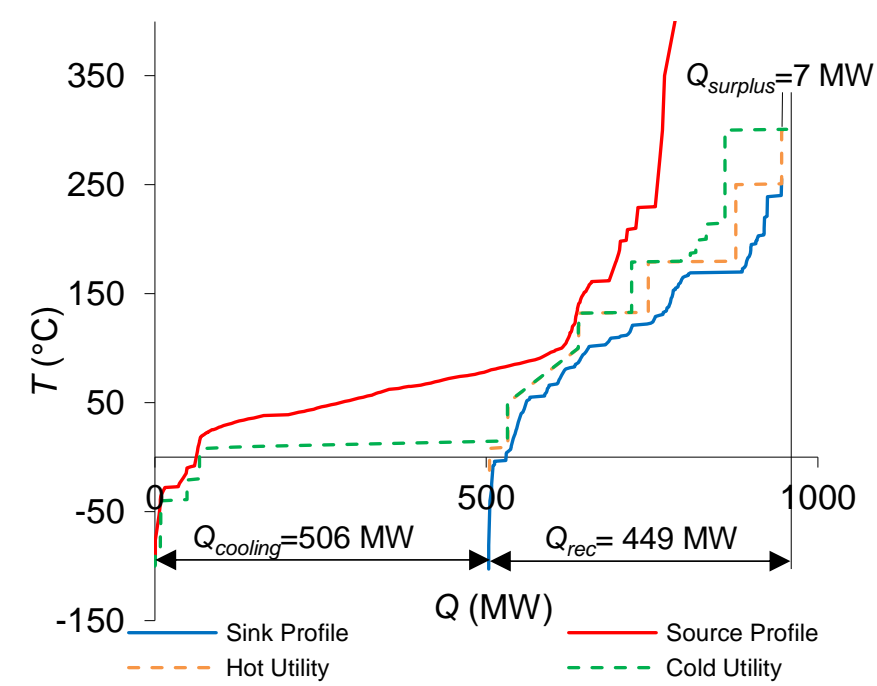

Figure $7 \mathrm{TSC}$ of the cluster after implementation of all the suggested changes to the utility system [8].

In detail the suggested measures are:

- Implementation of a site wide hot water circuit to deliver excess heat across the cluster

- Increased recovery of low pressure (LP) steam

- Changes in several heat exchangers to steam generation at higher pressure

- Changes in several heat exchangers to use steam at lower pressure

Implementation of all these measures results in an increase in heat recovery of $129 \mathrm{MW}$ (heat recovery in the current cluster amounts to a total of $320 \mathrm{MW}$, whereas $449 \mathrm{MW}$ are possible if the suggested measures are implemented). This means that all the external hot utility demand is eliminated, plus a surplus of $7 \mathrm{MW}$ heat is generated. The resulting TSC are shown in Figure 7. Based on this analysis specific site-wide energy efficiency measures can be investigated in detail. Table 2 shows the results for the sum of the minimum heating demands of the individual plants (72 MW, i.e. $79 \mathrm{MW}$ more than the theoretical heating demand if cross-company energy collaboration is implemented).

In a final analysis the amount of excess heat for the ideal fully integrated cluster was determined [8]. If all the above suggested energy measures are implemented, the amount of internal heat recovery is maximized and the amount of excess heat available from the cluster is at a minimum. Figure 8 shows the GCC representing the minimum amount of excess heat available. It can be seen that there are $23 \mathrm{MW}$ of heat available at temperatures above $110{ }^{\circ} \mathrm{C}$ and $226 \mathrm{MW}$ above $50{ }^{\circ} \mathrm{C}$. How excess heat from the cluster can be utilized is discussed in the following sections. 


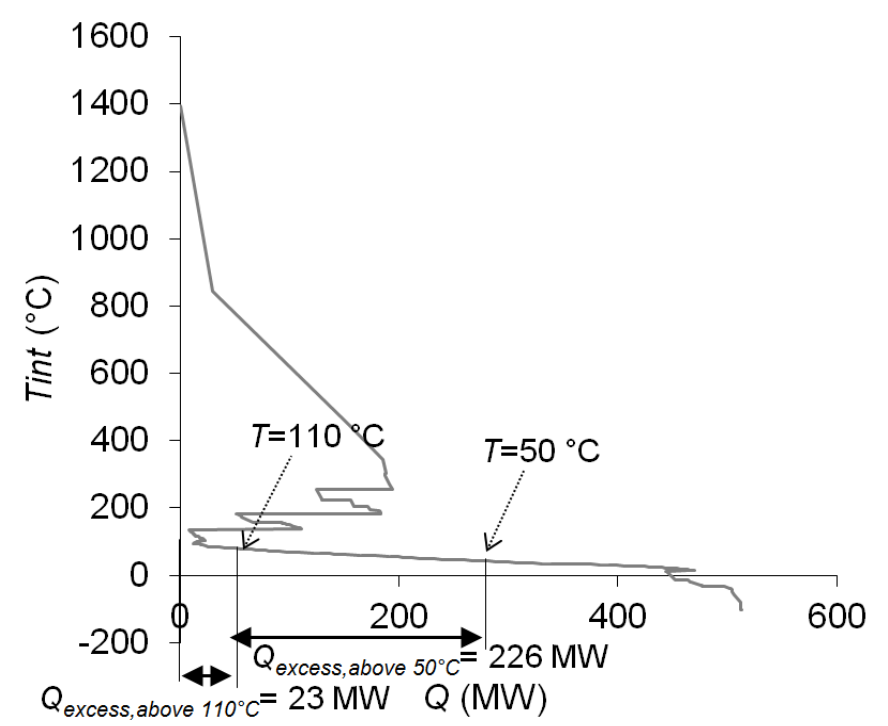

Figure 8 GCC showing the amount of excess heat available from the cluster after implementation of suggested energy efficiency measures.

\subsection{Cooling systems integration}

The results presented in this section are based on data collected during the previous TSA study [2]. Most of the cooling within the cluster is performed by two interconnected vapour-compression refrigeration systems located at the steam cracker site. The systems are steam and electricity driven and deliver cooling at six levels $\left(9{ }^{\circ} \mathrm{C},-21^{\circ} \mathrm{C},-40{ }^{\circ} \mathrm{C},-62{ }^{\circ} \mathrm{C},-84{ }^{\circ} \mathrm{C}\right.$ and $\left.-100{ }^{\circ} \mathrm{C}\right)$. The cooling loads of the current refrigeration levels are given in Table 1. More detailed results can be found in [17].

\section{Improvements to the current refrigeration system}

Process integration tools, such as pinch analysis and exergy analysis are used to target for cooling capacity and resulting shaft power savings in the cluster's main refrigeration systems. One way to decrease exergy flow rate losses caused by the current design of the refrigeration systems and thereby increase their energy efficiency is to improve the way cold utility is used in the process. Process stream data and utility data from a previous TSA study were used to construct the exergy efficiency CC for process and utility streams below ambient temperature.

Figure 9 shows the hot process streams and the current cold utility profile (dotted line) of the cluster's process streams below ambient temperature.

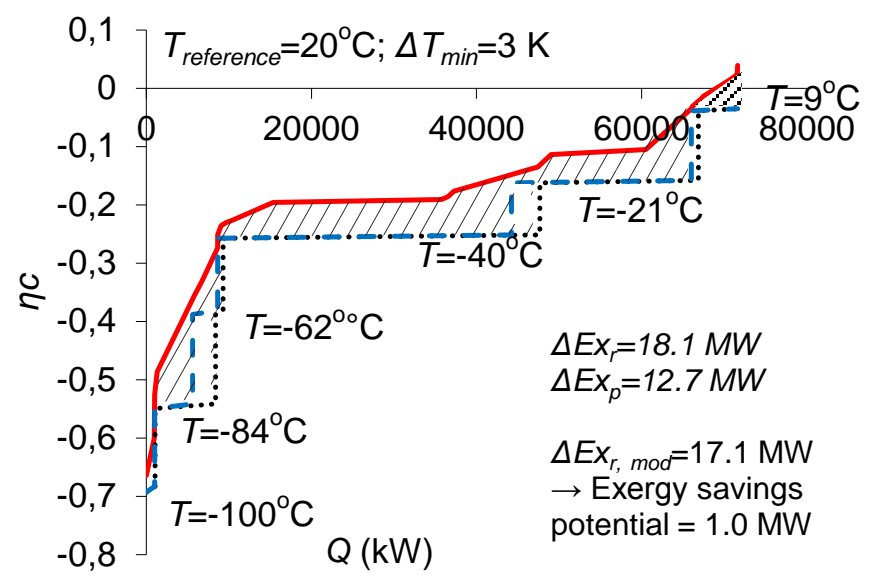

Figure 9 Exergy CC showing the hot process streams that need cooling below ambient temperatures, the current utility profile (dotted line) and the suggested improved utility profile (dashed line) at the current cold utility levels [17]. 
The area between the two curves (i.e. $\Delta E x_{\mathrm{r}}-\Delta E x_{\mathrm{p}}$ ) corresponds to $18.1-12.7=5.4 \mathrm{MW}$. This is the exergy flow rate being lost due to the way heat is transferred between the process streams and the cold utility system.

Figure 9 illustrates the design of an improved cold utility system (dashed line). The current cooling levels are kept, but instead cold utility is used at as high temperature as possible. Thereby the area between the utility and process curve is decreased ( $\triangle$ Exr of current refrigeration system $=$ 18.1 MW; $\Delta E x_{\mathrm{r}}$, mod of the suggested refrigeration system $=17.1 \mathrm{MW}$ ), which corresponds to avoided exergy flow rate losses of approximately $1 \mathrm{MW}$, as shown in

Figure 9.

Taking into account $\eta_{e x}$, shaft power savings of approximately $1.5 \mathrm{MW}$ can be achieved by the suggested changes to the utility system, corresponding to $5.4 \%$ of the total shaft power consumed in the refrigeration systems.

\section{$\underline{\text { Increased recovery of low temperature utility }}$}

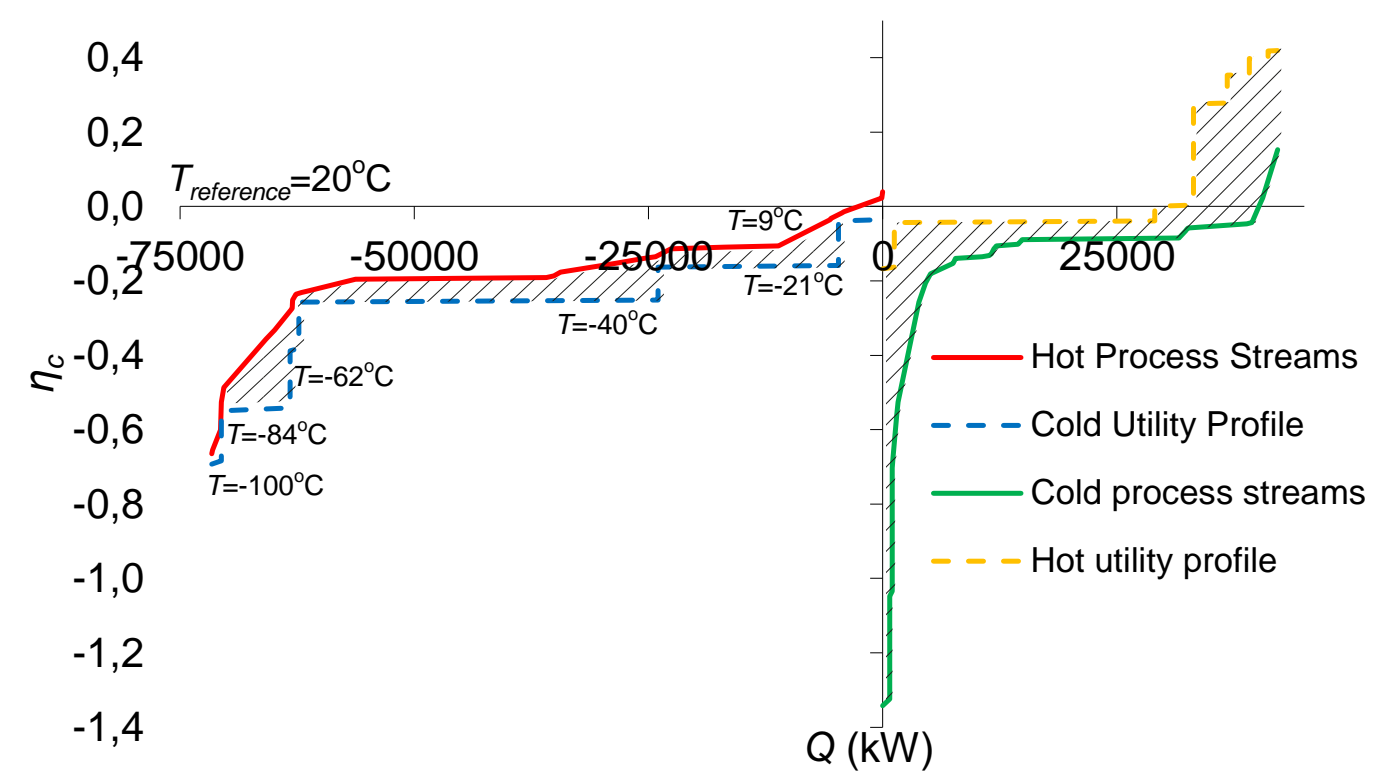

Figure 10: Exergy TSP showing process streams at the steam cracker plant cooled by refrigerants and the cold utility profile (left), the total sites cold streams below ambient-T and the respective hot utility profile (right) [17]. 


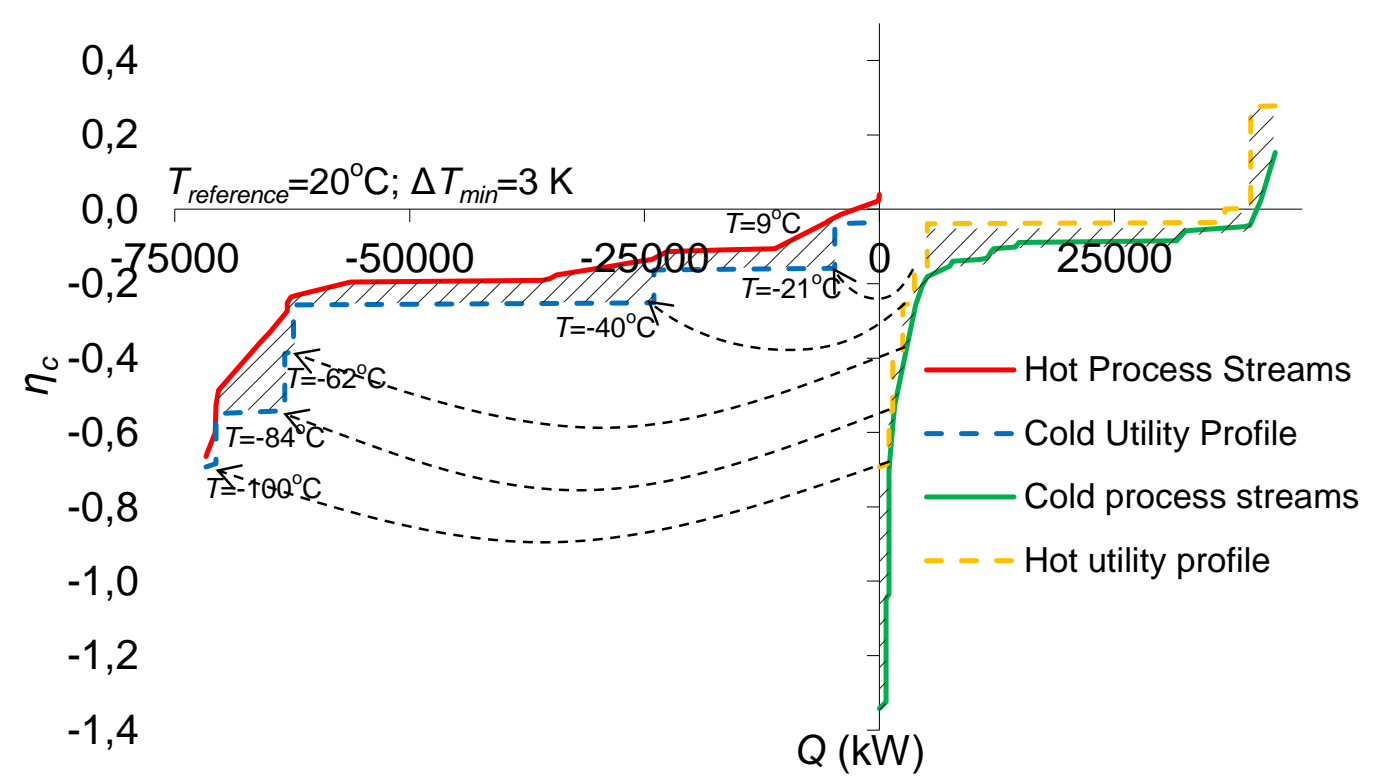

Figure 11: Exergy TSP showing process streams at the steam cracker plant cooled by refrigerants and the cold utility profile (left), the total sites cold streams below ambient-T and a suggested improved hot utility profile (right) [17].

The left side of Figure 10 shows hot process streams (full line) and the cold utility profile (dashed line). The right side shows cold process streams (full line) and the current hot utility (dashed line) used for process heating. The area between the curves (striped) represents the exergy flow rate losses caused by heat transfer between the utility system and the process streams. It can be seen at the right side of Figure 10 that there is a large gap between the hot utility profile and the cold process streams. This means that the exergy flow rate losses due to heat transfer are high and that there is a potential for the recovery of cooling capacity. A utility system utilizing optimal cooling loads (retaining the cluster's existing cold utility levels) was designed. This is shown in the righthand side of Figure 11.

The potential for increased recovery of cold utility and the resulting avoided exergy flow rate losses are summarized in Table 3. It is shown that by changing the utility system in order to recover more cooling capacity from cold process streams, while retaining the current utility levels, it is possible to decrease the exergy flow rate losses in the cooling system by $1.63 \mathrm{MW}$. Taking into account $\eta_{e x}$, shaft power savings of $2.5 \mathrm{MW}$ can be achieved. This is approximately $10 \%$ of the total shaft power consumption of the cooling systems. In addition the use of $6.3 \mathrm{MW}$ of utility steam at gauge pressure levels between 2 bar and 28 bar is avoided.

Table 3: Summary of the potential for cooling recovery from cold process streams and the resulting avoided exergy flow rate losses considering the current cold utility levels.

\begin{tabular}{lcc}
\hline $\begin{array}{l}\text { Cold utility } \\
\text { level }\end{array}$ & $\begin{array}{c}\text { Potential additional recovery of cold utility from cold process } \\
\text { streams }[\mathrm{MW}]\end{array}$ & $\begin{array}{c}\text { Avoided exergy flow rate losses } \\
{[\mathrm{MW}]}\end{array}$ \\
\hline $\mathrm{C} 2 /-100^{\circ} \mathrm{C}$ & 1.0 & 0.7 \\
$\mathrm{C} 2 /-84^{\circ} \mathrm{C}$ & 0.4 & 0.2 \\
$\mathrm{C} 2 /-62 \mathrm{C}$ & 0.9 & 0.4 \\
$\mathrm{C} 3 /-40^{\circ} \mathrm{C}$ & 1.3 & 0.3 \\
$\mathrm{C} 3 /-21^{\circ} \mathrm{C}$ & 0.2 & 0.03 \\
$\mathrm{C} 3 / 9^{\circ} \mathrm{C}$ & & 1.63 \\
\hline $\mathrm{Sum}$ & 3.8 & \\
\hline
\end{tabular}




\subsection{Biorefinery integration with an existing cluster}

Ethylene is the main intermediate product and feedstock to most of the clusters' processes. Therefore in a more detailed process integration study a process producing ethylene from lignocellulosic biomass was investigated. The cluster currently imports about $200 \mathrm{kt}$-ethylene/yr. Therefore this production capacity is assumed in the following case study. Further assumptions about process parameters are presented in [5].

One way to produce ethylene from ligno-cellulosic biomass is via a two-step process. In step 1 the carbohydrates in the biomass are converted via fermentation to ethanol. In step 2 the ethanol is dehydrated to ethylene. A similar sugarcane-based process already exists in Brazil. Currently extensive research on processes producing ethanol from lignocellulosic biomass is conducted. In the presented study a process which uses lignocellulosic biomass for ethanol production is assumed.

Process simulation was used to simulate a lignocellulosic ethanol production and the ethanol dehydration process in order to obtain the necessary data for further process integration investigation.

In order to quantify the savings potential that can be obtained by process integration of the two step ethanol production process and the chemical cluster the reference process configuration was defined as stand-alone operation of the two separate processes for lignocellulosic ethanol production.

Pinch analysis of the separate processes showed that their combined minimum heating and cooling demands are $131 \mathrm{MW}_{\text {heating,min }}$ and $196 \mathrm{MW}_{\text {cooling,min }}$ (for details, the reader is referred to reference [5]). Based on these results different ways for improved process integration were investigated. A background/foreground analysis showing both the ethanol and ethylene plant is shown in Figure 12. As can be seen in the figure, the minimum heating and cooling demand of the combined processes is decreased by $49 \mathrm{MW}$ to $82 \mathrm{MW}_{\text {heating,min }}(-37 \%)$ and $55 \mathrm{MW}$ to $141 \mathrm{MW}_{\text {cooling,min }}$ ($28 \%$ ), respectively. The decrease is mainly due to the possibility of transferring excess heat from the ethanol dehydration process to the ethanol production process $\left(\mathrm{Q}_{\text {recovered }}=44.5 \mathrm{MW}\right)$. The rest of the energy savings is due to a lower energy demand when ethanol is directly delivered from the production plant to the dehydration plant in the vapor phase. Thereby ethanol condensation at the ethanol plant, transportation between two separate sites and evaporation of ethanol in the dehydration plant is avoided.

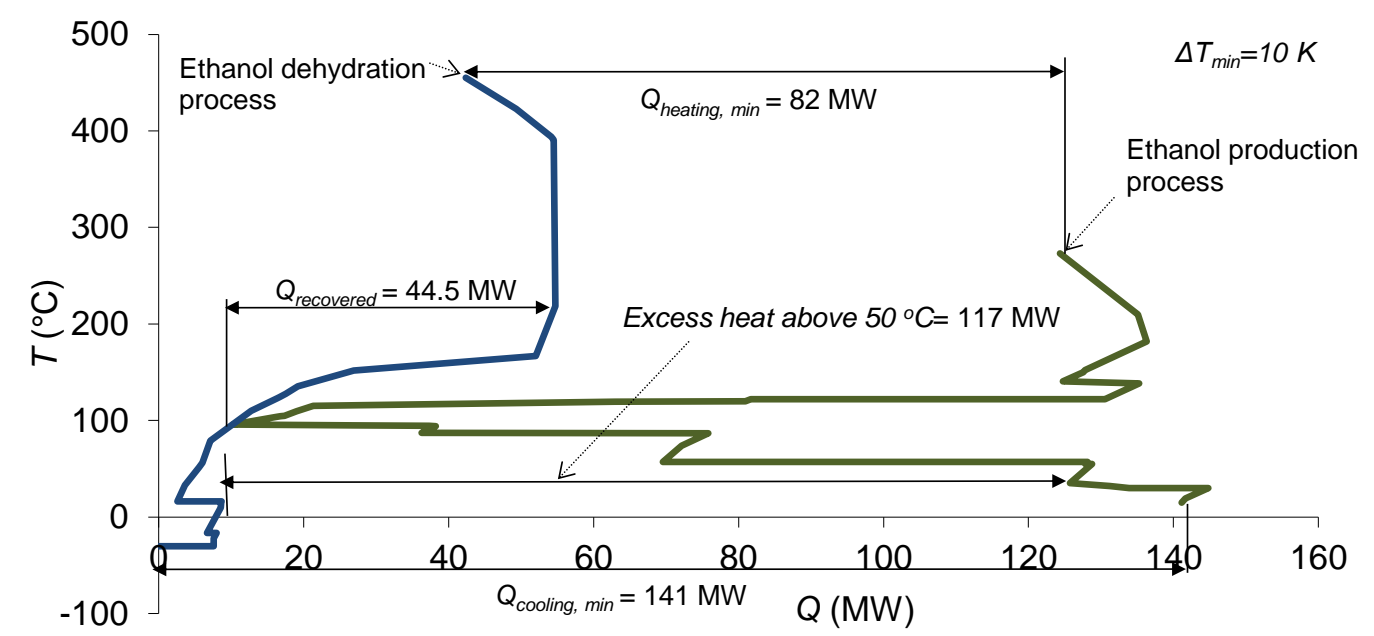

Figure 12 Background/Foreground analysis of the ethanol production and ethanol dehydration process. 
Figure 8 shows that after implementation of all the suggested site-wide energy efficiency measures ${ }^{2}$ there are $23 \mathrm{MW}$ of excess heat available from the cluster above $110{ }^{\circ} \mathrm{C}$ (this is the necessary temperature for transferring the heat to the biorefinery via a utility system). At this temperature the heat deficit of the biorefinery is $9 \mathrm{MW}$. This shows a potential for transferring excess heat from the cluster to the biorefinery process of $9 \mathrm{MW}$.

The approach presented in this paper can be applied to several biorefinery concepts. The heat integration potential and overall suitability for integration of the biorefinery with the existing clusters can be assessed and thereby the most suitable biorefinery can be determined.

\subsection{Increased utilisation of excess heat}

Figure 8 and Figure 12 indicate that there are large amounts of excess heat available from both the cluster and the biorefinery. Heat exchange between these two has been estimated, see Section 3.4. Summing up all excess heat at a temperature above $50{ }^{\circ} \mathrm{C}$ gives a potential of $343 \mathrm{MW}$ (117 MW from the biorefinery $+226 \mathrm{MW}$ from the cluster) for external use such as on-site biomass drying, export to a district heating network, or conversion to electric power in an organic Rankine cycle.

\section{CONCLUSION AND DISCUSSION}

The transition of exiting industrial chemical production processes towards sustainability has to be conducted in a systematic and efficient way. This paper presented how a set of process integration methods can be used in order obtain a holistic view of the energy system in an industrial cluster and based on this identify ways to achieve increased energy efficiency as well as a feedstock transition from fossil towards renewable feedstocks.

Pinch analysis was used to target for the minimum heating and cooling demand of single process plants and identify specific measures to decrease the use of hot and cold utility of the plant. Results from pinch analysis studies of individual processes provide guidance for efficiency improvement investments at one site and can be used as input for site wide heat integration studies using total site analysis tools. Based on this mapping of the energy systems within the existing cluster suitable biorefinery concepts can be identified following the suggested procedure.

The main findings of an illustrative case study are:

- There is a large heat integration potential within each constituent plant, resulting in an excess of low grade heat.

- In addition, there is a large site-wide heat integration potential if common utility systems are implemented.

- The companies were not aware of these potential energy savings.

- Adopting a common approach enabled for increased collaboration between the companies (at the investigation stage).

- A common utility system configuration designed for maximum heat integration can provide guidance when designing specific common heat integration measures.

- Biorefinery integration shows large heat integration potential between the two process units of the investigated biorefinery.

- Heat integration of the biorefinery with the existing cluster can potentially lead to heat savings

- Large amount of excess heat suitable for e.g. district heating can be released and exported from the cluster and the biorefinery.

General conclusions from the presented work are:

\footnotetext{
${ }^{2}$ If all the energy efficiency measures suggested are implemented, the maximum amount of excess heat is utilized within the cluster. This in return means that the minimum amount of excess heat is available for alternative use.
} 
- Investments in energy efficiency at one site are often not feasible as they result in an excess of low quality utility at the specific site. Clusters often consist of several plants with different plant owners. Plant operators usually have no detailed knowledge about the energy and material flows in their neighboring plants. The approach used in this study is a way to make all plant operators aware of common heat integration opportunities and their associated efficiency gains. It was shown that by considering the whole cluster it is possible to find ways for improved redistribution of recovered utility leading to an overall increase in energy efficiency of the cluster.

- There are several different biorefinery processes available and at the same time biogenic feedstock is limited and expensive. Biorefineries strongly differ in heating, cooling and electricity demand. The suggested holistic approach can be used to compare integration of different biorefinery concepts with an existing industrial cluster and identify the most suitable biorefinery from a process integration point of view.

- The suggested approach enables investigation of integration of advanced biorefinery concepts with a site-wide utility network which can lead to several advantages such as economics of scale because a biorefinery delivering feedstock to several plants can have a larger production volume, sharing large investment and risks of implementing a new technology.

- Other potential synergies in addition to heat integration with the existing plants can be identified using the suggested approach. Excess capacity in the existing cluster (e.g. in boilers or refrigeration systems) can be identified and possible use of this capacity within the new process can be investigated. Alternatively, excess heat from the biorefinery can be used in the cluster instead thereby avoiding expensive boiler extension.

All this is possible if a holistic approach is applied where energy and material flows throughout the total site are considered and this knowledge is utilized for integration of the most suitable biorefinery process to minimize resource consumption and costs.

During this research project other factors which are important for collaboration across company borders besides the technical feasibility were identified. One of the challenges of using the proposed methodology is to investigate long term development plans for such clusters. Each company within a cluster has more or less far-reaching plans for future development of its own plant and such plans should be included in the TSA effort. However, data collection is a complicated process, especially if data is uncertain and about potential future plant developments. Other factors include, e.g. ownership structure of the companies, design of business models promoting collaboration across company borders, policy instruments supporting the implementation of energy efficiency measures and renewable materials, etc. Further research work is ongoing to study these factors and develop strategies to overcome non-technical obstacles in industrial cluster collaborations.

\section{ACKNOWLEDGEMENTS}

This work was carried out under the auspices on the Energy Systems Programme, which is funded primarily by the Swedish Energy Agency. Additional funding was provided by the Swedish Energy Agency's programme for Energy Efficiency in Industry, as well as by participating industrial partners from the chemical cluster in Stenungsund. The authors would particularly like to thank Åsa Lindqvist, Maria Arvidsson and Björn Lundin for their excellent work during their respective MSc thesis projects. 


\section{REFERENCES}

[1] IEA. Energy Technology Perspectives 2012: Pathways to a Clean Energy System. OECD Publishing 2012.

[2] Hackl R, Andersson E. TSA Stenungsund. Göteborg: Chalmers University of Technology; 2010. Report No.: 131484. available from: publications.lib.chalmers.se/publication/131484.

[3] Andersson E, Franck P- $\AA$, Hackl R, Harvey S. TSA II Stenungsund - Investigation of opportunities for implementation of proposed energy efficiency measures. Göteborg: Chalmers University of Technology; 2011. Report No.: 155735. available from: publications.lib.chalmers.se/publication/155735.

[4] Hackl R, Harvey S. Opportunities for Process Integrated Biorefinery Concepts in the Chemical Cluster in Stenungsund. Göteborg: Chalmers University of Technology; 2010. Report No.: 131485. available from: publications.lib.chalmers.se/publication/131485.

[5] Arvidsson M, Lundin B. Process integration study of a biorefinery producing ethylene from lignocellulosic feedstock for a chemical cluster. Master's Thesis. Göteborg: Chalmers University of Technology, 2011. available from: publications.lib.chalmers.se/publication/140886.

[6] Matsuda K, Hirochi Y, Tatsumi H, Shire T. Applying heat integration total site based pinch technology to a large industrial area in Japan to further improve performance of highly efficient process plants. Energy 2009;34:1687-92.

[7] Stijepovic MZ, Linke P. Optimal waste heat recovery and reuse in industrial zones. Energy 2011;36:4019-31.

[8] Hackl R, Andersson E, Harvey S. Targeting for energy efficiency and improved energy collaboration between different companies using total site analysis (TSA). Energy 2011;36:4609-15.

[9] Isaksson J, Pettersson K, Mahmoudkhani M, Åsblad A, Berntsson T. Integration of biomass gasification with a Scandinavian mechanical pulp and paper mill: Consequences for mass and energy balances and global $\mathrm{CO}_{2}$ emissions. Energy 2012;44:420-8.

[10] Arvidsson M, Heyne S, Morandin M, Harvey S. Integration opportunities for substitute natural gas (SNG) production in an industrial process plant. Chem Eng Trans 2012;29:331-6.

[11] Brau J-F, Morandin M, Berntsson T. Hydrogen for oil refining via biomass indirect steam gasification: energy and environmental targets. Clean Tec Env Pol 2013. 10.1007/s10098-0130591-9. in press.

[12] Heyne S, Thunman H, Harvey S. Extending existing combined heat and power plants for synthetic natural gas production. Int J Energ Res 2012;36:670-81.

[13] Sandén B. Systems Perspectives on Biorefineries. 1st ed. Göteborg, Sweden: Chalmers University of Technology; 2012. available from: http://www.chalmers.se/en/areas-ofadvance/energy/cei/Pages/Systems\%20Perspectives\%20on\%20Biorefineries\%202012/Systems -Perspectives-on-Biorefineries.aspx

[14] Duić N, Guzović Z, Kafarov V, Klemeš JJ, Mathiessen B vad, Yan J. Sustainable development of energy, water and environment systems. Applied Energy 2013;101:3-5.

[15] Ammar Y, Joyce S, Norman R, Wang Y, Roskilly AP. Low grade thermal energy sources and uses from the process industry in the UK. Appl Energy 2012;89:3-20.

[16] Raissi K. Total site integration. PhD Thesis. University of Manchester Institute of Science and Technology, 1994.

[17] Hackl R, Harvey S. Applying exergy and Total Site Analysis for targeting refrigeration shaft power in industrial clusters. Energy 2013. 10.1016/j.energy.2013.03.029. in press.

[18] De Jong E, Van Ree R, Kwant IK. Biorefineries: Adding Value to the Sustainable Utilisation of Biomass. Amsterdam: IEA Bioenergy; 2009. available from: www.ieabioenergy.com/DownLoad.aspx ?DocId=6421. 
[19] Cherubini F. The biorefinery concept: Using biomass instead of oil for producing energy and chemicals. Energ Convers Manage 2010;51:1412-21.

[20] Hackl R, Arvidsson M, Harvey S. Process integration study of a biorefinery producing ethylene from lignocellulosic feedstock for a chemical cluster. In: Ban M, Duic N, Guzovic Z, editors. 6th Dubrovnik Conference on Sustainable Development of Energy, Water and Environment Systems 2011 Sep 25 - 29; Dubrovnik, Croatia. Dubrovnik; 2011. p 21 (Paper 928).

[21] Brown SM. The drive for refinery energy efficiency. Petroleum Technology Quaterly 1999:45-55.

[22] Thomé B. Systems engineering: principles and practice of computer-based systems engineering. 1st ed. Hoboken, NJ, USA: Wiley; 1993.

[23] Aspen Technology. AspenPlus - Getting started building and running a process model. Burlington, USA: Aspen Technology, Inc.; 2009.

[24] Linnhoff B, Flower JR. Synthesis of heat exchanger networks: I. Systematic generation of energy optimal networks. AIChE J 1978;24:633-42.

[25] Kemp IC. Pinch analysis and process integration. 2nd ed. Oxford, UK: ButterworthHeinemann; (1st edition Linnhoff et al. 1982). 2007.

[26] Smith R. Chemical process design and integration. 1st ed. Chichester West Sussex, UK: Wiley; 2005.

[27] Klemes J, Friedler F, Bulatov I, Varbanov P. Sustainability in the Process Industry: Integration and Optimization. 1st ed. New York, NY, USA: McGraw-Hill Professional; 2010.

[28] Dhole VR, Linnhoff B. Total site targets for fuel, co-generation, emissions, and cooling. Comput Chem Eng 1993;17:101-9.

[29] Perry S, Klemes J, Bulatov I. Integrating waste and renewable energy to reduce the carbon footprint of locally integrated energy sectors. Energy 2008;33:1489-97.

[30] Feng X, Pu J, Yang J, Chu KH. Energy recovery in petrochemical complexes through heat integration retrofit analysis. Appl Energy 2011;88:1965-82.

[31] Bandyopadhyay S, Varghese J, Bansal V. Targeting for cogeneration potential through total site integration. Appl Therm Eng 2010;30:6-14.

[32] Botros BB, Brisson JG. Targeting the optimum steam system for power generation with increased flexibility in the steam power island design. Energy 2011;36:4625-32.

[33] Linnhoff B, Dhole VR. Shaftwork targets for low-temperature process design. Chem Eng Sci 1992;47:2081-91.

[34] Lindqvist $\AA$. Process integration study for increased energy efficiency of a PVC plant. Master's Thesis. Göteborg: Chalmers University of Technology, 2011. available from: publications.lib.chalmers.se/publication/143109. 